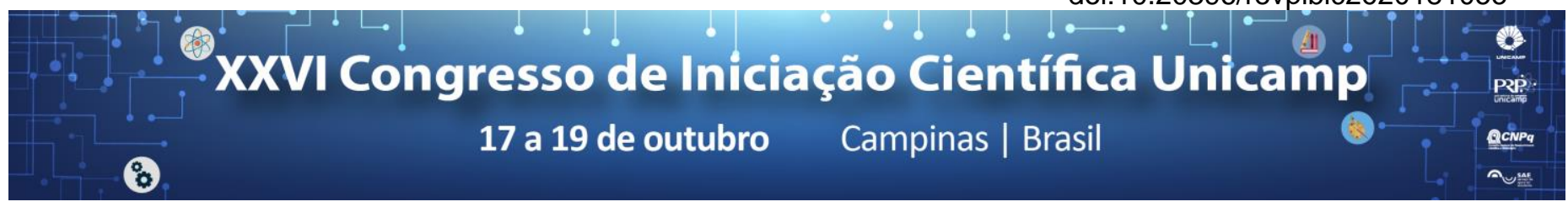

\title{
Sistema de rastreamento de veículos de transporte público com interface ao usuário
}

\author{
Michael Ramos de Almeida, Leandro Ronchini Ximenes
}

\section{Resumo}

O projeto aqui descrito teve como proposta a criação de uma aplicação para dispositivos móveis no sistema operacional Android, visando a melhoria na qualidade do transporte público, tendo como cenário a cidade de Campinas, interior de São Paulo.

\section{Palavras-chave: \\ transporte público, dispositivos móveis, mapas}

\section{Introdução}

O projeto de criação de um sistema de rastreamento de veículos de transporte público, com interface ao usuário, surgiu do desejo de promover uma alternativa de baixo custo e de fácil implementação que pudesse amenizar alguns problemas ligados ao uso do transporte público de passageiros (e.g. ônibus), como problemas relacionados à acessibilidade ${ }^{1}$, à segurança e ao conforto dos usuários. A solução mais direta deste problema seria ter maiores investimentos nos transportes públicos, aumentando a frota de veículos e/ou implementando sistemas otimizados de controle de trafego?

Dada justificativa econômica fornecida pelo poder público para uma limitação de gastos nesse setor, a partir daí surgiu-se a ideia de criar uma solução alternativa de baixo custo para amenizar, ou mesmo solucionar, alguns dos problemas encontrados no cenário estudado. É sabido que um novo sistema com interface ao usuário para o monitoramento do transporte público seria uma ferramenta muito interessante, uma vez que ao usuário poderiam ser disponibilizados informações úteis para sua melhor tomada de decisão. O sistema proposto em si é um software baseado na plataforma para dispositivos moveis Android, que foi desenvolvido para exibir ao usuário informações sobre percursos de ônibus, distância e caminho até o ponto mais próximo a pé, local onde o ônibus se encontra.

\section{Resultados e Discussão}

A aplicação produzida funciona somente no trecho estudado, uma região de Campinas, porque não era objeto de estudo simular o funcionamento em toda a cidade, um bairro apenas, com algumas linhas, seria suficiente. No entanto ele é escalável, podendo ser adaptado a mais regiões. É possível ver as rotas que nele foram inseridas, pontos de ônibus e informações sobre o veículo (que foram inseridas de forma fictícia). No decorrer do desenvolvimento foi notado que o sistema de medição de tempo/percurso escolhido para monitorar um ônibus não é o melhor existente, porque só dá ao usuário uma estimativa (assim como a maioria dos softwares disponíveis atualmente). A melhor solução seria: ter um dispositivo GPS no veículo que monitorasse sua localização e enviasse a um servidor. A aplicação teria acesso a esses dados presentes no servidor, sobre a posição atual do veículo, e a partir disso conseguiria exibir num mapa (em tempo real, atualizando com frequência) a posição daquele veículo. Devido à dificuldade e tempo necessário para o desenvolvimento desse recurso, não teve como implementá-lo nesse projeto.
Outras melhorias que poderiam ser feitas em uma continuação do projeto: abrangência de mais plataformas e/ou uma versão que poderia ser acessada por um computador comum.

\section{Conclusões}

O sistema de rastreamento público com interface ao usuário, portanto, foi finalizado com toda estrutura e recursos citados até então, aumentando o conhecimento do aluno sobre programação (Java) e dispositivos móveis (Android), assim como transporte público e pesquisa acadêmica. Gerando um projeto executável para smartphones com sistema operacional Android.

Na Figura 1 é possível ver um dos recursos da aplicação, que exibe informações sobre o veículo que está a caminho de determinados pontos de ônibus.

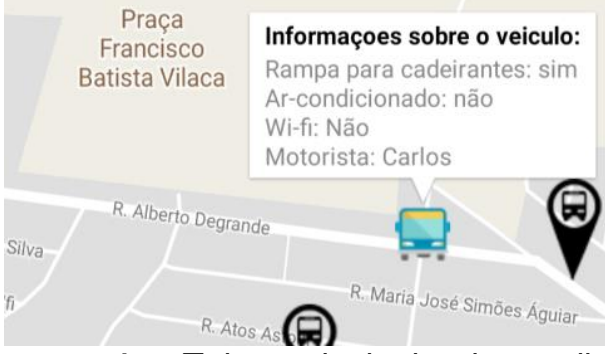

Figura 1. Tela principal da aplicação exibindo informações sobe um ônibus.

Além desse recurso, é valido ressaltar que a aplicação também: mostra o caminho que o usuário deve fazer da sua posição atual até um ponto de ônibus escolhido, retornando a ela o tempo que ela levará para chegar até o local, andando, e qual melhor caminho seguir; informações nos pontos de ônibus sobre quais linhas passam por ele; a rota que o ônibus percorre e a posição atual do usuário com um ícone no mapa e um texto informando o local por escrito.

\section{Agradecimentos}

Programa Institucional de Bolsas de Iniciação Científica e de Iniciação em Desenvolvimento Tecnológico e Inovação

\footnotetext{
1 SILVA, Daniel Luis Nithack e. Utilização de um Sistema de Informação Geográfica visando melhorar o transporte exclusivo para pessoas portadoras de deficiência física. 2004. 141 f. Tese (Mestrado) - Curso de Engenharia Civil, Faculdade de Engenharia Civil, Arquitetura e Urbanismo, Universidade Estadual de Campinas, Campinas, 2004.

${ }^{2}$ DEZANI, Henrique. OTIMIZAÇÃO DO FLUXO DO TRÁFEGO URBANO MODELADO EM REDES DE PETRI UTILIZANDO ALGORITMO GENÉTICO. 2012. 46 f. Tese (Doutorado) - Curso de Engenharia Elétrica, Faculdade de Engenharia Elétrica e de Computação, Universidade Estadual de Campinas, Campinas, 2012.
} 